\title{
TOTAL IMPACT EVALUATION OF TRANSPORTATION SYSTEMS
}

\author{
József ROHÁCS*, Dániel ROHÁCS \\ Dept of Aeronautics, Naval Architecture and Railway Vehicles; \\ Budapest University of Technology and Economics, Budapest, Hungary
}

Received 28 May 2018; revised 12 November 2018, 14 February 2019; accepted 6 April 2019

\begin{abstract}
Impact assessment, in general, includes the environmental safety and security considerations, and cost/cost-benefit analysis of the used sources. As usual, the impact is evaluated at two levels: (1) impact during operation (usage) related to a chosen operational unit (e.g., running distance $[\mathrm{km}]$, operational time $[\mathrm{h}]$ or calendar time $[\mathrm{h}]$ ), (2) the life-cycle (project life-cycle) impact. The environmental impact is characterized by the chemical and noise emissions. Safety and security are estimated by risks. Costs are calculated based on the required financial support and caused losses. All these calculations are related to the individual vehicles or vehicles with average behaviours. The investigation of sustainability impact requires a wider evaluation and approach, for example, by also including production and recycling beside the operational aspects. This paper generalizes the impact analysis. At first, it considers all types of impacts including the direct (e.g., accidents) and indirect long-term effects (e.g., health problems caused by emissions). All the impacts are expressed as costs. The defined Sustainable Transportation Performance Index (STPI) is the Total Life-Cycle Cost (TLCC) related to the unit of transport work. As such, it combines the life-cycle emissions evaluation and transport costing methods. It contains the total operational and total impact costs. The proposed approach introduces three new specific features in the impact analysis: (1) the impact is evaluated on the transportation system level, (2) the impact is estimated as the total value (including all the related sub-systems and elements, like vehicles, transport infrastructure, transport flow control, etc.), (3) proposes a unique index to describe the total impact. The paper describes the general equations and the developed methodology for the estimation of the total impact and analyses its applicability. The preliminary results demonstrate the applicability of the defined index and its evaluation methodology. It also shows the limitations of traditional cost models. Further test results and wider application of the methodology will be provided in a series of follow up papers by the research team.
\end{abstract}

Keywords: total impacts, transportation means, safety, security, emission, noise, external costs.

\section{Notations}

$\mathrm{CO}_{2}$ - carbon-dioxide;

GDP - gross domestic product;

GHG - greenhouse gas;

GI - group of impacts;

KPI - key point indicator;

pkm - passenger-kilometre;

PPP - purchasing power parity;

SGI - sub-groups of impacts;

$\mathrm{SO}_{2}$ - sulphur-dioxide;

STPI - sustainable transportation performance index;

TILCC - total impact life-cycle cost;

TIPI - total impact performance index;

tkm - tonne-kilometre;

TLCC - total life-cycle cost;

TLCW - total life-cycle work;

TM - transport mean;
TOLCC - total operational life-cycle cost;

TOPI - total operation performance index;

TPI - transportation (total) performance index;

vkm - vehicle-kilometre.

\section{Introduction}

Nowadays, impact analysis is a necessary, important and integrated part of projects developing new technologies or solutions. However, impact analysis deals often only with the environmental impact. The global GHG emissions already reached $46 \mathrm{Gt}$ (given in $\mathrm{CO}_{2}$ equivalent) in 2013 (WRI 2018). The transportation segment is one of the major contributor factors by emitting $14 \%$ of the GHG (Edenhofer et al. 2014). The global transportation system uses more than $100 \mathrm{EJ}$ energy, $95 \%$ of which comes from

*Corresponding author. E-mail: jrohacs@vrht.bme.hu 
petroleum-based fuels, largely gasoline and diesel. $1 / 3$ of the energy consumption of the vehicles in the transportation system relates to kinetic energy, while $2 / 3$ to heat losses.

Transportation plays a determining role in the economy (Rohacs 2005) and its volume increases with GDP growth (Baninster, Stead 2002). The European practice in emissions reduction (EU 2016) demonstrates that for the last 15 years only, the transportation sector's emission is greater than the total emission levels of 1990 due to the increasing number of vehicles and their usage.

The transportation related white papers and vision documents define the future KPIs and goals from an emission reduction point of view. For example, the White Paper (EC 2011) on the future of transportation, defines its key goals for 2050 as the following:

- no more conventionally-fuelled cars in cities;

- $40 \%$ use of sustainable low carbon fuels in aviation; at least $40 \%$ cut in shipping emissions;

- $50 \%$ shift of medium distance intercity passenger and freight journeys from road to rail and waterborne transport;

- all of which will contribute to a $60 \%$ cut in transport emissions by the middle of the century.

Generally, the methods of the environmental impact assessment of the vehicles and transportation systems are well developed (Ntziachristos et al. 2009; Smit et al. 2010; Demir et al. 2011) and with systemically applicable tools (Upham et al. 2004; De Ceuster et al. 2004).

On a higher management level related to sustainable development, the effects of environmental impact are defined in the form of externalities. Externality is the cost or benefit of any actions that is experienced by the unrelated third parties (Buchanan, Stubblebine 1962). This approach converts all the effects to a cost value. The method is well applicable to investigate special aspects, like the support of electric (Buekers et al. 2014) and hybrid vehicles (Samaras, Meisterling 2008). It is also used to study and evaluate an economic sector, such as transportation (Van Essen et al. 2008; Maibach et al. 2008). The special value of the update of the "Handbook on the External Costs of Transport" (Van Essen et al. 2019, 2008; Maibach et al. 2008) includes: (1) the good description of methodology, (2) the use of a large number of references and real data sources, (3) the use of the safety (external costs caused by accidents) and congestion factors in the list of externalities. For example, in the case of passenger cars, the external costs induced by accidents reaches $50 \%$ of all the externalities excluding congestions. Congestions increase the external cost by 40\% (Van Essen et al. 2008). The complexity of the evaluation and the lack of applicable estimation methods might be characterized by the example of the climate change and congestion effects. For passenger cars in Europe, the climate change effects are estimated at 14.4 and $84.1 \mathrm{mln} € /$ year for the low and high scenarios respectively. The costs of road congestions are defined between 98.4 and 161.3 mln $€ /$ year (Van Essen et al. 2008).
As it can be seen: (1) there are numerous studies and papers describing the possible translation of the impacts into costs or cost-benefits, while (2) the results are not so accurate (such as previously cited costs of road congestions).

Another interesting study was published by Chester and Horvath (2009). They investigated the life-cycle energy use and GHG emissions, considering the emissions caused by infrastructure, fuel production, and supply chains. They found that the total life-cycle energy use and GHG emissions contribute an additional 63\% for road, $155 \%$ for rail, and $31 \%$ for air transportation systems over the vehicle tailpipe values. Generally, investigating criteria air pollutants shows that the vehicle non-operational components often dominate the total emissions. The lifecycle criteria air pollutant emissions might be 1.2 to 12 (in case of $\mathrm{SO}_{2}$ emission for the light rail transport even up to 800) times higher than those related to vehicle operation (Chester, Horvath 2009). Therefore, the total impact (taking into account the infrastructure development, energy generation, etc.) may "change the game". This point of view may show that even the use of electric cars is not such a clear and green transport system as it looks for the first time.

This paper intends to make a further step and take into account all the costs related to the use of transportation systems, such as the costs related to vehicle production, road infrastructure, or transport flow management. In addition, the externalities should be included into the total impact evaluation. The total impact must be determined for the life-cycle, which can be related to the unit of usage, such as $[\mathrm{pkm}]$ or $[\mathrm{tkm}]$.

The objective of this paper is to create an index for total impact evaluation and to develop a methodology (methodological framework) for the evaluation and application of the new total impact index. This paper generalizes the impact analysis. This approach introduces three new specific features in impact analysis: (1) the impacts are evaluated on the transportation system level, (2) the impacts are estimated as their total value, including all the related sub-systems and elements, like vehicles, transport infrastructure, transport flow control, etc., (3) defines a unique index describing the total impact in the form of a total cost function.

\section{Total impact assessment - a general approach}

The impact is defined as the effect of a system or concept on a measured variable or on other systems. In the case of transportation, this means for example the effects of the vehicles, transportation means or transportation systems on society, nature, built environment or large technical systems (as shown in Figure 1). The impact can be described in various forms, from direct and short time (such as transport accidents) to indirect and long-term (like health problems caused by climate change) effects. The impact has an influence on nature through direct (damage 
of trees, forests due to chemical emissions) and indirect effects, such as the changes initiated by climate change. The built environment and technical systems might be damaged or even destroyed by the short direct impacts (like accidents, for example airplane crash into electric power station) and long-term effects (such as corrosion of the technical systems caused by chemical emissions).

The demand for the design of sustainable systems catalysed the development of methods of indicator identification, evaluation and selection. Probably the most used definition of sustainability is given by WCED (1987): “... we must meet the needs of the present in ways that do not compromise the ability of future generations to meet their needs...". Sustainability is characterized by factors, performance, indicators and indexes (Gudmundsson 2001; Litman 2009; Rohács, Simongáti 2007; Dobranskyte-Niskota et al. 2007, 2009) and depends on various factors, including economic and societal considerations. The vehicles, fleets and transportation means have their own characteristics and performance measures (including for example the geometrical characteristics, weight, maximum speed, etc.), see Figure 2. The indicators are variables selected and defined to measure the progress towards an objective, such as the development of sustainable transportation

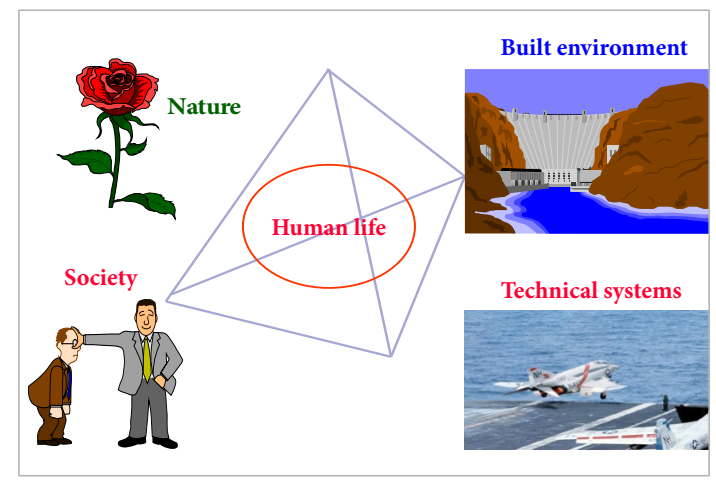

Figure 1. Tetrahedron of the total impact

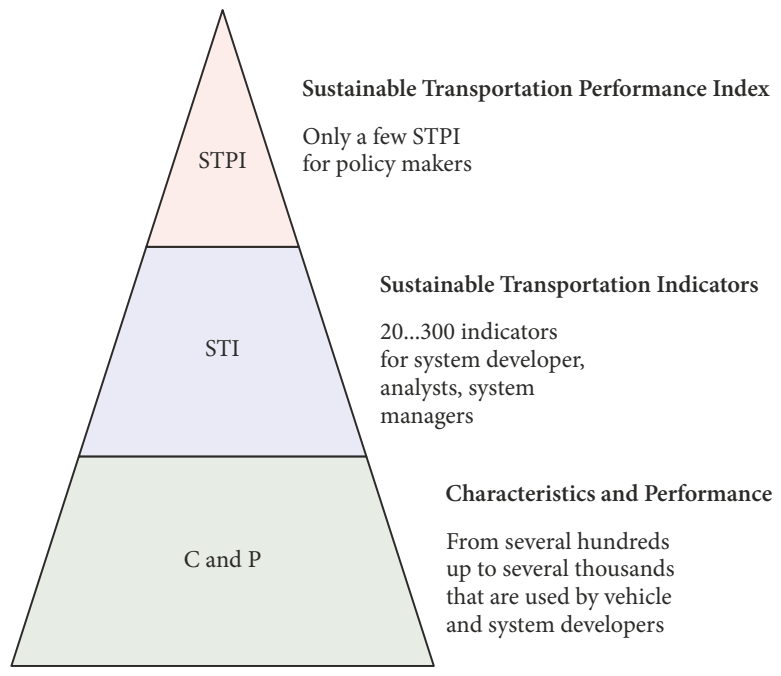

Figure 2. The pyramid of indicators (source: Litman 2009)
(Gudmundsson 2001; Litman 2009; Dobranskyte-Niskota et al. 2007, 2009). They are usually expressed in the following framework:

- indicator data - values used in indicators;

- indicator type - nature of data used by the indicator (qualitative or quantitative, absolute or relative);

- indicator system - a process to define the indicators, collect and analyse data and apply the results;

- indicator framework - conceptual structure linking indicators to a theory, purpose or planning process;

- indicator set - a group of indicators selected to measure comprehensive progress toward goals;

- index (STPI) - a group of indicators aggregated into a single value (Litman 2009; Rohács, Simongáti 2007; Dobranskyte-Niskota et al. 2007, 2009).

Policy makers need objective information on the general impact, including all effects. Therefore, during the last $40 \ldots 60$ years, new approaches were introduced and applied in impact analysis. There are three major groups of new methods being developed:

- life-cycle (total life-cycle) effect (emissions, cost) calculations - that is used to analyse and evaluate the impact of the product (in this context, the vehicle);

- calculation of externalities - external cost of using or operating a given type of product, in this case a transportation means, or a type of vehicles;

- sustainability - that evaluates the use of resources as a long-term effect limiting or reducing the possibilities of future generations.

There are numerous high level, sophisticated solutions to calculate life-cycle emissions (Chester, Horvath 2009; Messagie et al. 2013), costs (Asiedu, Gu 1998; Hellgren 2007; Jun, Kim 2007; Furch 2016), to determine externalities (Buchanan, Stubblebine 1962; Van Essen et al. 2008), study the interactions of transport externalities and transport economy (Santos et al. 2010; Anas, Lindsey 2011) and interconnections of externalities and environmental assessment (Norris 2001; Profillidis et al. 2014). However, there are no well-developed and applicable solutions in existence for the evaluation of these groups of effects together with the use of a general or integrated performance index.

The authors of this paper investigated sustainable transportation and its development from various points of view. The combustion process and its effects was studied by numerical methods (Bicsák et al. 2010). A new, simple dynamic model was suggested for the dispersion of motorway traffic emissions (Csikós et al. 2015). A general estimation method was elaborated for transport mode emission evaluation (Tánczos, Török 2006). The sustainable transportation strategic development was defined (Michelberger, Nádai 2010). The link between climate change and the Hungarian road transport was investigated in depth (Tanczos, Torok 2007). Transport efficiency (Rohacs 2010), intermodal change (Rigo et al. 2007) and multi-criteria decision-making were investigated for a more adequate understanding of the basic transportation systems. A special sustainable transport performance index 
was developed (Rohács, Simongáti 2007; Simongáti 2010). The role of high level, state management in environment sustainability was studied (Kinzhikeyev et al. 2017). The developed competences were utilized in the evaluation of the impact of new technologies (Rohacs et al. 2013; Rohacs, D., Rohacs, J. 2016).

These methods works together with the life-cycle impact estimation methodologies (Van Essen et al. 2008; Maibach et al. 2008; Chester, Horvath 2009), the available input data (EU 2016; OECD 2018) and also with the additional information on the impact of the infrastructure or specific system elements. For the latter, see, for example, the impact from transport infrastructures (Horvath, Matthews 2005), life-cycle assessment of pavements (Santero et al. 2010) or, as a special example, the toxic effects of brake wear particles (Gasser et al. 2009). These studies allow a further step in the direction of the generalization of the impact evaluation and use the total impact calculation as a TILCC.

Developing a general approach means that all the impact, all the effects on nature, society, built environment and technical systems must be taken into account by single index, that might be used generally, independent of the economic or societal aspects of individual regions.

\section{Governing idea}

The total impact might be classified into five major groups:

- safety and security - inducing the direct and short time impact, such as accidents;

- environmental impact (chemical emission and noise) - generating direct and indirect medium- and long-term impact on people, nature, and the living world in general;

- system characteristics - system management, management of the transport operation processes that, for example, cause congestions;

- system support - infrastructure, supply chains, upstream and downstream processes that have a considerable effect on the environment and society;

- use of resources - that might be defined as perishable effects, e.g., use of land, minerals sources.

The last GI in this paper are related to economic effects that take into account the perishable nature of given resources, such as loss of time when waiting for transport, loss of agricultural or natural land, use of oil, reduction in the value of real estate due to emissions, noise or vibration originating from the transportation systems.

The proposed and introduced new approach generalizes the impact analysis: (1) it takes into account all types of impact (safety, security, environmental impacts, system management, system support, use of resources), (2) it summarizes all the impact related to the transportation systems, e.g., the manufacture, operation, and recycling of the vehicles, the required infrastructure, surveillance and control systems, and so on.

This paper recommends the use of a simplified and unique index to evaluate the total impact, in the form of total costs induced by all life-cycle effects of transportation system related to a unit of transportation work [pkm] or $[\mathrm{tkm}]$ :

$$
T P I=\frac{T L C C}{T L C W}=\frac{T O L C C}{T L C W}+\frac{T I L C C}{T L C W}=T O P I+T I P I,
$$

where: TPI (or STPI) is the transportation (total) performance index (or sustainable transportation performance index); TOPI is the total operation performance index; TIPI total impact performance index; TLCC / TOLCC / TILCC are the total / total operational / total impact lifecycle cost; $T L C W$ is the total life-cycle work.

It is clear, that the TOPI as the operational cost of a given vehicle in a given transportation mode is well known, and is already used by the owners, operators, service providers. It plays the determining role in the users' selection of the vehicle, transportation mode and transportation chain. On the other hand, the TIPI deals with the externalities. This is the index that can be used in impact assessment.

The goal of this paper is to introduce a generalized index to evaluate the total impact of transportation systems and enable the comparison of various transportation means. As TOPI is assumed to be known, the following sections only describe the calculations of TIPI.

The TIPI summarizes all impact:

$$
T I P I=\sum_{i=1}^{n} T I P I_{i}=\frac{\sum_{i=1}^{n} T I L C C_{i}}{T L C W},
$$

where: $i=1,2, \ldots, n$ define the different groups of impact. In the case of transportations systems; $i$ can be defined as: safety and security, environmental impacts, system peculiarities, system support, use of resources.

\section{Methodology}

The individual TIPI $i$ in Equation (2) can be expressed as the sum of the different effects:

$$
\begin{aligned}
& T I P I_{i}=\frac{a}{T L C W_{i}} \forall i ; \\
& T L C W_{i}=\sum_{j=1}^{m} \sum_{k=1}^{l} \sum_{q=1}^{r} N_{j, k, q} \cdot W_{j, k, q},
\end{aligned}
$$

where:

$$
a=\sum_{j=1}^{m} \sum_{k=1}^{l} \sum_{q=1}^{r} N_{j, k, q} \cdot p_{j, k, q} \cdot I_{j, k, q} \cdot \sum_{v=1}^{u} o_{j, k, q, v} \cdot c_{j, k, q, v},
$$

where: $j=1,2, \ldots, m$ describes the subgroups of impact; $k=1,2, \ldots, l$ defines the TMs; $q=1,2, \ldots, r$ represents the types or groups of the given transportation system; $v=1$, $2, \ldots, u$ identifies the different forms of consequences; $N$ is the number of sub-group elements contributing to the impact; $q, p$ is the parameter of the given types or groups of system elements that cause the investigated effects; $I$ is the impact indicator of the given system element; $o$ the 
outcomes / consequences of the impact defined by $I$ or caused by the events, situations related to the $I$ indicator; $c$ is the conversion coefficient to assess the (external) cost; $W$ is the work done during the investigated period defined by $p$.

As it can be seen, Equation (3) includes many terms. That is intentional, as the TIPI must take into account all the effects. There is reason while Equation (3) is defined in the form of a "hierarchical sum". After a short study of this formula, a systematic model hierarchy might seem to appear that could be simply supported by using a set of special tables. However, that approach has a weakness. There are no well applicable formulas for the calculation of all the effects in cost format. Generally, developed cost models depend on the economic, ecologic and societal conditions.

Let us examine the use Equation (3) through an example. Parameter $i=1$ means impact group relating to safety and security. In both cases, safety or security events, such as a car accident, may simply cause delay and repair expenses, but possible additional personal injuries can result in large extra external costs. Of course, the safety and security group present a broad range of events based on size, outcomes, etc. and they must be estimated separately using models appropriate to the class of the events. Therefore, as a first approximation, $j=1$ defines the safety aspects, while $j=2$ deals with security. The parameter $k$ identifies the transportation means, such as road, water, etc. transport. The $q$ parameter depicts the type of vehicles, for example in the case of road transport, a personal car or even the personal car type depending on the level of TIPI calculation. In this last case, $N_{j, k, q}$ means the number of different cars in the investigated sectors or regions. The $p$ parameter might be given as annual (or life-cycle) averaged running distance of the given car category in the given regions. Naturally, numerous safety indicators (Jalonen, Salmi 2009) could be used, basically any that relate to causes of safety problems, or risks. In this case, they can be classified as the following:

- external factors not directly related to the vehicle (or transport system) like bad weather conditions;

- risks depending on the vehicle structure, (transport systems organization and structure) like manoeuvring characteristics;

- technical failures, such as engine failure, or increase in fuel consumption due to engine failure;

- failures in control and management, such as failure in traffic control systems;

- errors caused by the human controlling the vehicle;

- errors, failures caused by passengers or transported goods.

Each sub-sub-group may contain several, up 20 indicators. As a first approximation, the indicator $I$, can be harmonized with the $p$ parameter. Here, for example, the impact indicator can be defined as a risk of accident related to the given unit of $p$ parameter, namely the risk of accident related to unit distance. Depending on the required accuracy and available preliminary information (e.g., statistical data on the operational history), the safety performance indicators, such as failure rates can be integrated into a few indicators. Even in a simple case, three indicators can be applied, such as accident, hard accident with human injuries and serious accidents with fatalities. If these three indicators are integrated into one, as a single risk of accidents, then the accident outcomes, such as hard and serious accidents might be defined by weighting coefficients $o$. The coefficient $c$ is the cost related to one unit of outcome $o$.

The $p$ parameter also plays the role of a weighting function that depends on the vehicle or system characteristics and parameters, since the indicators depend on the real characteristics of the real vehicles, systems or environment. For example, the accident rate depends on the colour of the car, GDP of the country or regions, on the driving culture, or the driver assisting systems. Therefore, the given car category could be further specified, for example petrol or diesel engine, being black, white or yellow and so on. The consequences $o$, describe the function of consequences that take into account the outcomes form the impact characterized by the performance indicator. The consequences might be divided into more categories harmonized with the applied impact indicators. For example, a simple accident might cause damages in: (1) the vehicle, (2) the transport infrastructure, (3) the cultural values. The consequences are defined as a function of outcomes, as they depend on the level of economy and thus might change over the life-cycle frame.

By taking into account the functions of parameters, impact indicators, consequences and conversion coefficients, Equation (3) can be rewritten in several other forms:

$$
\operatorname{TIPI}_{i}=\frac{a_{1}}{T L C W_{i}} \forall i
$$

where:

$$
\begin{aligned}
& a_{1}=\sum_{j=1}^{m} \sum_{k=1}^{l} \sum_{q=1}^{r} N_{j, k, q} \cdot f_{p_{j, k, q}}\left(p_{j, k, q}\right) \cdot f_{I_{j, k, q}}\left(I_{j, k, q}\right) \times \\
& \sum_{v=1}^{u} f_{o_{j, k, q, v}}\left(o_{j, k, q, v}\right) \cdot f_{c_{j, k, q, v}}\left(c_{j, k, q, v}\right) ; \\
& \operatorname{TIPI}_{i}=\frac{a_{2}}{T L C W_{i}} \forall i
\end{aligned}
$$

where:

$$
\begin{aligned}
& a_{2}=\sum_{j=1}^{m} \sum_{k=1}^{l} \sum_{q=1}^{r} N_{j, k, q} \cdot f_{p_{j, k, q}}\left(p_{j, k, q}\right) \times \\
& \sum_{v=1}^{u} f_{I}\left(I_{j, k, q, v}\right) \cdot f_{o_{j, k, q, v}}\left(o_{j, k, q, v}\right) \cdot f_{c_{j, k, q, v}}\left(c_{j, k, q, v}\right),
\end{aligned}
$$

where: $f$ are functions depending on the given index $x$ (namely $P, I o, c$ ) at the defined next indexes.

The developed methodology can be applied, for example, to a given vehicle, equivalent (average) vehicle, fleet, 
or to a transportation company or TMs. Therefore, this methodology is structured in a hierarchic form. For example, as a first approximation, the safety impact of the accidents as external costs can be determined by the following simple formula, applicable for a small taxi company:

$$
\begin{aligned}
& T I P I_{\text {safety, accident }}=\frac{\sum_{i=1}^{n} N_{i} \cdot p_{i} \cdot I_{s a, i} \cdot \sum_{j=1}^{k} o_{i, j} \cdot c_{i, j}}{\sum_{i=1}^{n} N_{i} \cdot p_{i}}= \\
& \underline{\sum_{i=1}^{n} N_{i} \cdot p_{i} \cdot I_{s a, i} \cdot\left(o_{i, d} \cdot c_{i, d}+o_{i, i n} \cdot c_{i, i n}+o_{i, f} \cdot c_{i, f}\right)}, \\
& \sum_{i=1}^{n} N_{i} \cdot p_{i}
\end{aligned}
$$

where: $i=1,2, \ldots, n$ defines the car categories used by the taxi company; $N_{i}$ number of cars of the given category; $p_{i}$ is the annual average mileage of the $i$ category of cars; $I_{s a, i}$ safety accident rate (risk) of the given category of the cars; $o_{d}, o_{i n}, o_{f}$ are the weighting coefficient, ratio of damage, injure and fatal accidents taking into account the third parties involved in the accidents (therefore, the sum of the weighting coefficients is more than 1$) ; c_{d}, c_{i n}, c_{f}$ are the cost conversion coefficients of damage, injuries and fatalities.

As it can be understood, the hierarchy of the methodology allows the use of the created TIPI or TPI index on different levels; as individual cars, transport company, city transport, etc. and on the different segments (evaluating only the safety aspects or only the greenhouse effect).

\section{Applicability}

A team of researchers, under the guidance of the authors, applied the methodology to prove its applicability. The methods were applied to several study cases based on real world data. The list of cases includes impact estimation, identification, evaluation and selection of the applicable cost models and the study of the method's accuracy. Using the index, new cost models were also developed.

The data required were collected from a variety of information sources, including statistical data, references, research reports (CORDIS 2006; Maibach et al. 2008; Van Essen et al. 2008; Edenhofer et al. 2014; WRI 2018; EU 2016). It has to be noted, that data is very sensitive to a set of complex circumstances such as economic development, societies, structure of the transportation systems and factors depending on the culture. To support this claim, selected conversion coefficients of fatalities for several European countries are shown in Table.

Table shows that the conversion coefficients and other parameters (e.g., outcome functions) are very different for different conditions, countries or regions. These applied parameters, indicators, weighting and conversion coefficients highly depend on the economic, technical (technological) and social factors.

Therefore, the developed methodology must be adapted to the real situations, real conditions and real regions.

For example, the fatality costs as the social value and statistical life are usually estimated by the willingness to pay method (Upham et al. 2004; De Ceuster et al. 2004; Buchanan, Stubblebine 1962; Litman 2009). It is interesting, that the willingness is rather greater at countries with higher GDP, where citizens are willing to pay from 70 to 200 years' net income to avoid a transport fatal accident (as shown in Figure 3). This paper wishes to underline that the fatality costs might be overestimated, when the citizens are willing to pay $60 \ldots 160$ years of GDP per capita, which is unavailable. As seen in Figure 3, relatively higher amounts are payed by countries with lower GDP. The fatality costs are changing with increasing GDP, but it seems, again, that the greater growth belongs to the poorer countries, as shown in Figure 4. However, Figure 4 also demonstrates that the fatality costs correlate with the GDP

\begin{tabular}{|c|c|c|c|c|c|c|}
\hline \multirow{2}{*}{ Country } & Fatality & Severe injury & Slight injury & Fatality & Severe injury & Slight injury \\
\hline & \multicolumn{3}{|c|}{$€ 2002$, factor prices } & \multicolumn{3}{|c|}{$€ 2002$ PPP, factor prices } \\
\hline Austria & 1760000 & 240300 & 19000 & 1685000 & 230100 & 18200 \\
\hline Cyprus & 704000 & 92900 & 6800 & 798000 & 105500 & 7700 \\
\hline Estonia & 352000 & 46500 & 3400 & 630000 & 84400 & 6100 \\
\hline Finland & 1738000 & 230600 & 17300 & 1548000 & 205900 & 15400 \\
\hline France & 1617000 & 225800 & 17000 & 1548000 & 216300 & 16200 \\
\hline Germany & 1661000 & 229400 & 18600 & 1493000 & 206500 & 16700 \\
\hline Hungary & 440000 & 59000 & 4300 & 808000 & 108400 & 7900 \\
\hline Italy & 1430000 & 183700 & 14100 & 1493000 & 191900 & 14700 \\
\hline Latvia & 275000 & 36700 & 2700 & 534000 & 72300 & 5200 \\
\hline Lithuania & 275000 & 38000 & 2700 & 575000 & 78500 & 5700 \\
\hline Norway & 2893000 & 406000 & 29100 & 2055000 & 288300 & 20700 \\
\hline Poland & 341000 & 46500 & 3300 & 630000 & 84500 & 6100 \\
\hline Spain & 1122000 & 138900 & 10500 & 1302000 & 161800 & 12200 \\
\hline
\end{tabular}
and can be defined by approximation formulas.

Table. Estimated values for casualties avoided, defined in $€$ for year 2002 and in PPP (source: CORDIS 2006) 


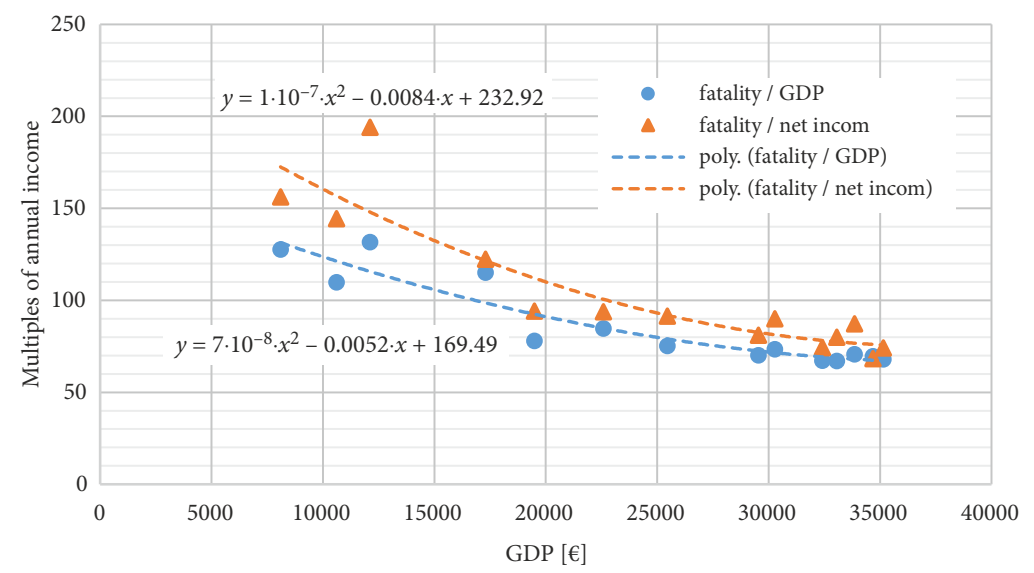

Figure 3. Willingness to pay to avoid transport accident fatalities (ratio of fatality costs per GDP and fatality costs per persons' net income for EU countries in year 2010)

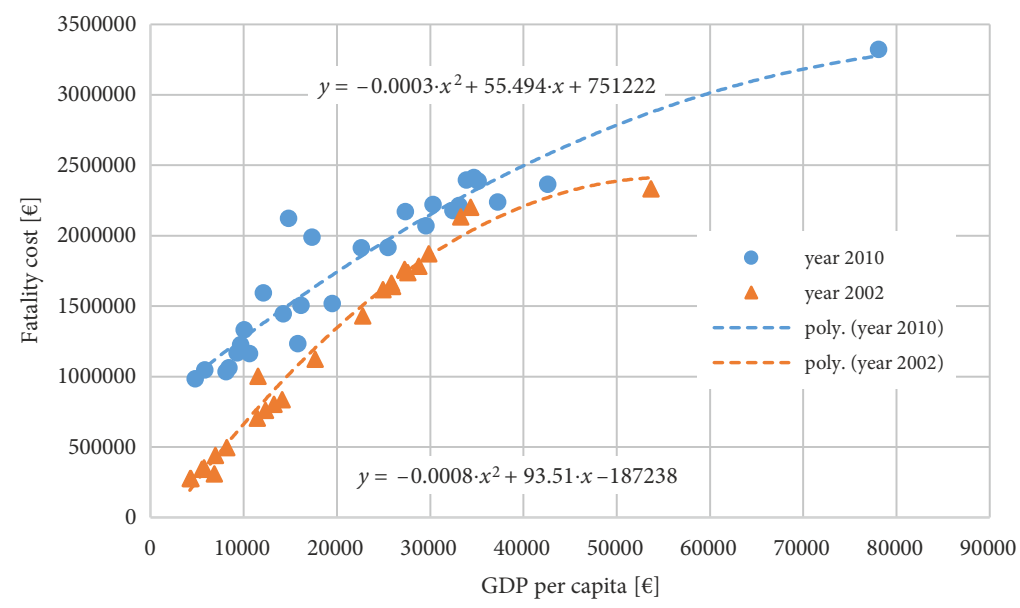

Figure 4. The estimated fatality costs as function of GDP per capita

The introduced methodology was applied to calculate the TIPI, and compare various transportation means. In this paper, only the safety group of impact indices is described.

Of course, there are several challenges and barriers, that can make the use of the recommended methodology difficult. One of the most important fact is that, the TIPI (and TPI) must be determined for the complete life-cycle, while the numerous aspects; indicators, parameters and coefficients of the cost-models may be subject to change. At first, this is the reason while the total impact must be determined for the unit of work. At second, the change models applied by the TLCC analysis might be used in these estimations, too. For example, the changes in labour cost, price of materials, energy used in building the infrastructure, etc. might be modelled as it is done in TLCC calculation.

This calculation uses Equations (4) and (5). For supporting the impact estimation, a special table model is developed, that contains the following sections in horizontal rows:

- number of rows;

- region or area of investigation (like Europe, Hungary, or Budapest Mass Transport Company, small logistic company, etc.);
- code number - completed from the indexes;

- GI (depicted by index $i$ );

- SGI (identified by index $j$ );

- TM (indexed by $k$ );

- number of studied elements or merit, i.e. value of the chosen governing parameter;

- applied general parameters:

- applied parameters, their appellations and values (for each parameter);

- formula (used for the determination of the general parameter) and calculated value;

- general impact indicators:

- applied indicators, their appellations and values;

- formula (used for the determination of the general impact indicator) and its calculated value;

- outcomes (determined by the use of the same methods as those applied to general parameter and general impact indicator calculations);

- cost coefficient (determined by the use of the same methods as those applied to general parameter and general impact indicator calculations);

- work (two columns: dimension and value);

- results (summarized in 5 columns: $\operatorname{TIPI}_{i, j, k, q}$, TIPI $_{i, j, k}$, TIPI $_{i, j}$, TIPI $_{i}$ and TIPI). 


\section{Results}

The introduced TIPI and the developed methods were also tested and validated. The example results, relating to Hungarian and EU transportation systems, are shown in Figures 5 and 6.

Figure 5 shows the breakdown of the safety total impact determined for Hungary and Europe. As shown, the costs related to health consequences (fatality, severe injury) are higher in Hungary due to the larger safety risks.

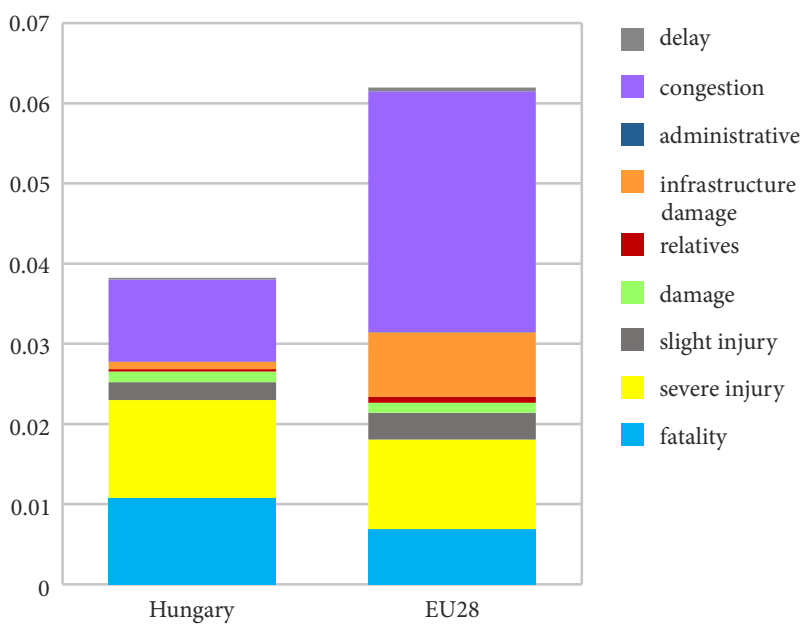

Figure 5. Safety TIPI determined for the passenger cars [€ ct/pkm]
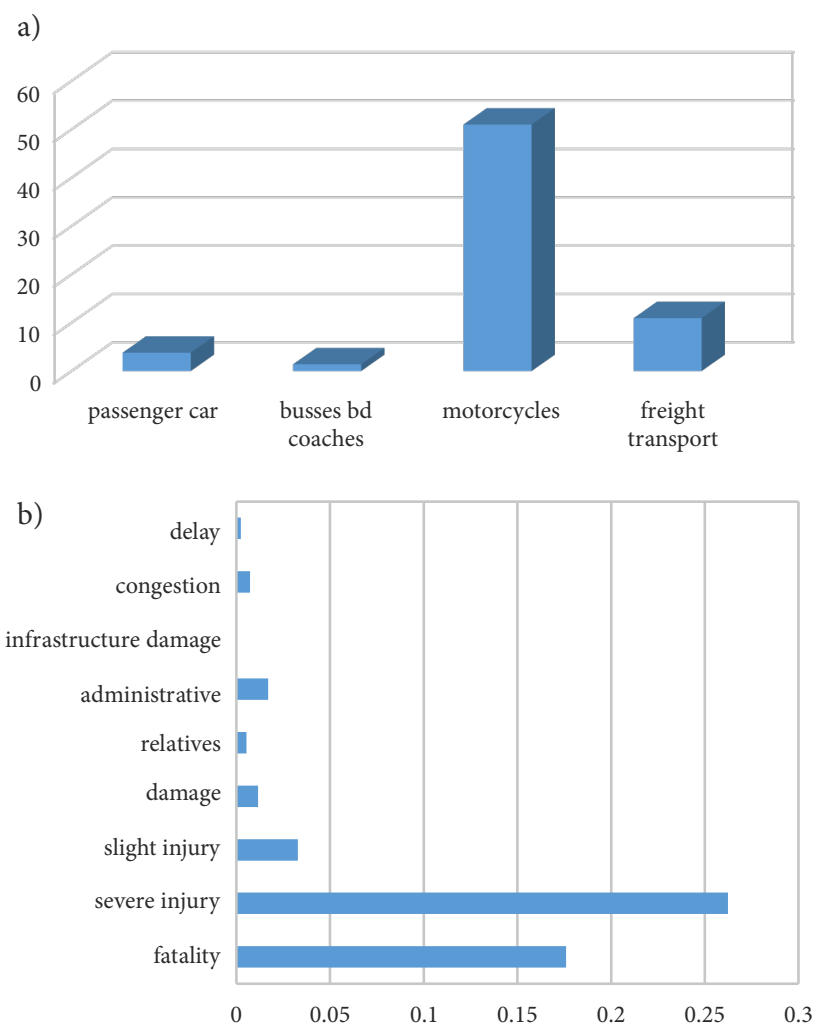

Figure 6. Safety total impact performance ([€ ct/pkm] for passenger car, buses and motorcycles and [€ ct/tkm] for freight transport) in Hungary for year 2014 (a) and costs $[€ \mathrm{ct} / \mathrm{pkm}]$ breakdown for motorcycles (b)
The administrative cost for Europe is higher than in Hungary, due to the higher operational costs of the offices, wage of employees and the more complex investigation processes. Interestingly, the congestion costs compared to the other elements are relatively high, mostly due to the higher value of time and more congestions (especially in the more developed countries). In some cities, the marginal external costs induced by congestion might reach $2 . . .2 .5 € / \mathrm{vkm}$.

In 2014, in Hungary, many accidents with fatal and severe injuries involved motorcycles, while these were operated at relatively small average distances, so the impact per unit transport work is very high, as seen in Figure 6. A small investigation on the potential cause indicated that this is primarily caused by the pleasure and "racing" runs.

Figures 5 and 6 demonstrates that there is no limitation on applicability of the method in various impact estimations. On the other hand, there are some limitations caused by available cost models. Assumptions might be useful in the simplification of the cost-models, harmonization of the results with stakeholders and supporting societal acceptance. These assumptions may have two roles: reducing the uncertainties and reducing the time-effects.

\section{Conclusions}

Nowadays, in the era of climate change, sustainability is a major objective of the development methods of future vehicles and transportation systems. There are many international (EU supported) and national projects that estimate the impact of various transportation means, different elements of the transport systems on the environment, economy and societies. Several related works introduced the idea to evaluate the transport impact with external costs. The developed methodologies intend to integrate all impact elements into one unique index.

This paper takes a further step and recommends the use of a TIPI as the total life-cycle external costs related to the vehicles' unit of transportation work. This way it combines the total life-cycle emission evaluation methods and transport costing methods.

The paper defines the methodology to calculate the suggested new TPI. This method can be used to perform comparative studies of transportation means, different transportation networks, emerging new solutions, new technologies (such as electric vehicles). The short explanation and discussion sections introduce the proposed idea and methodology.

The future applicability of this developing methodology requires the creation of a series of models, especially cost models for the different impacts. The available models today have many uncertainties and even unclear dependence on economic and societal factors.

The developed methods were tested and the concept was validated as a separate study. The example results presented here show the applicability of the recommended TIPI, the developed methods of calculations and some possible outcomes of the process. 


\section{Acknowledgements}

The developed method is applying to impact analysis of the "Development of the Small 4 seat and Small Unmanned Cargo Aircraft with Hybrid Propulsion System" supported by Hungarian National Project EFOP-3.6.1-162016-00014 "Investigation and Development of the Disruptive Technologies for e-Mobility and their Integration into the Engineering Education (IDEA-E)".

\section{Funding}

Hungarian National Project EFOP-3.6.1-16-2016-00014 "Investigation and Development of the Disruptive Technologies for e-Mobility and their Integration into the Engineering Education (IDEA-E)".

\section{Disclosure statement}

Authors declare they have not any competing financial, professional, or personal interests from other parties.

\section{References}

Anas, A.; Lindsey, R. 2011. Reducing urban road transportation externalities: road pricing in theory and in practice, Review of Environmental Economics and Policy 5(1): 66-88. https://doi.org/10.1093/reep/req019

Asiedu, Y.; Gu, P. 1998. Product life cycle cost analysis: state of the art review, International Journal of Production Research 36(4): 883-908. https://doi.org/10.1080/002075498193444

Baninster, D.; Stead, D. 2002. Reducing transport intensity, European Journal of Transport and Infrastructure Research 2(4): 161-178. https://doi.org/10.18757/ejtir.2002.2.4.3721

Bicsák, G.; Hornyák, A.; Veress, Á. 2010. Numerical simulation of combustion processes in a gas turbine, AIP Conference Proceedings 1493: 140-148. https://doi.org/10.1063/1.4765482

Buchanan, J. M.; Stubblebine, W. C. 1962. Externality, Economica 29(116): 371-384. https://doi.org/10.2307/2551386

Buekers, J; Van Holderbeke, M; Bierkens, J; Int Panis, L. 2014. Health and environmental benefits related to electric vehicle introduction in EU countries, Transportation Research Part D: Transport and Environment 33: 26-38. https://doi.org/10.1016/j.trd.2014.09.002

Chester, M. V.; Horvath, A. 2009. Environmental assessment of passenger transportation should include infrastructure and supply chains, Environmental Research Letters 4(2): 024008. https://doi.org/10.1088/1748-9326/4/2/024008

CORDIS. 2006. HEATCO: Developing Harmonised European Approaches for Transport Costing and Project Assessment. 6th RTD Framework Programme. Community Research and Development Information Service (CORDIS). Available from Internet: https://cordis.europa.eu/project/id/502481

Csikós, A.; Varga, I.; Hangos, K. M. 2015. Modeling of the dispersion of motorway traffic emission for control purposes, Transportation Research Part C: Emerging Technologies 58: 598-616. https://doi.org/10.1016/j.trc.2015.03.027

De Ceuster, G.; Van Herbruggen, B.; Logghe, S.; Proost, S. 2004. TREMOVE 2.2: Model and Baseline Description. Report for European Commission. Service Contract B4-3040/2002/342069/ MAR/C.1. 156 p. Available from Internet: https://www.asser. nl/upload/eel-webroot/www/documents/TREMOVEreport. pdf
Demir, E.; Bektaş, T.; Laporte, G. 2011. A comparative analysis of several vehicle emission models for road freight transportation, Transportation Research Part D: Transport and Environment 16(5): 347-357.

https://doi.org/10.1016/j.trd.2011.01.011

Dobranskyte-Niskota, A. M.; Perujo, A.; Jesinghaus, J.; Jensen, P. 2009. Indicators to Assess Sustainability of Transport Activities. Part 2: Measurement and Evaluation of Transport Sustainability Performance in the EU27. EUR 23041 EN/2. Institute for Environment and Sustainability, Joint Research Centre, European Commission. 88 p. https://doi.org/10.2788/46618

Dobranskyte-Niskota, A. M.; Perujo, A.; Pregl, M. 2007. Indicators to Assess Sustainability of Transport Activities. Part 1: Review of the Existing Transport Sustainability Indicators Initiatives and Development of an Indicator Set to Assess Transport Sustainability Performance. Institute for Environment and Sustainability, Joint Research Centre, European Commission. EUR 23041 EN. 59 p. https://doi.org/10.2788/54736

EC. 2011. White Paper: Roadmap to a Single European Transport Area - Towards a Competitive and Resource Efficient Transport System. European Commission (EC). 31 p. Available from Internet: https://eur-lex.europa.eu/legal-content/EN/TXT/PDF/ ?uri=CELEX:52011DC0144\&qid=1588424022750\&from =EN

Edenhofer, O.; Pichs-Madruga, R.; Sokona, Y.; Farahani, E.; Kadner, S.; Seyboth, K.; Adler, A.; Baum, I.; Brunner, S.; Eickemeier, P.; Kriemann, B.; Savolainen, J.; Schlömer, S.; Von Stechow, C.; Zwickel, T.; Minx J. C. (Eds.). 2014. Climate Change 2014: Mitigation of Climate Change. Intergovernmental Panel on Climate Change (IPCC). 1454 p. Available from Internet: https://www.ipcc.ch/report/ar5/wg3

EU. 2016. Statistical Pocketbook 2016: EU Transport in Figures. Publications Office of the European Union (EU), Luxembourg. 160 p. Available from Internet: https://ec.europa.eu/ transport/facts-fundings/statistics/pocketbook-2016_en

Furch, J. 2016. A model for predicting motor vehicle life cycle cost and its verification, Transactions of FAMENA 40(1): 15-26.

Gasser, M.; Riediker, M.; Mueller, L.; Perrenoud, A.; Blank, F.; Gehr, P.; Rothen-Rutishauser, B. 2009. Toxic effects of brake wear particles on epithelial lung cells in vitro, Particle and Fibre Toxicology 6: 30. https://doi.org/10.1186/1743-8977-6-30

Gudmundsson, H. 2001. Indicators and performance measures for transportation, environment and sustainability in North America, Research Notes from NERI 148: 1-87. National Environmental Research Institute (NERI), Aarhus University, Denmark. Available from Internet: https://www.dmu.dk/1_viden/2_publikationer/3_arbrapporter/rapporter/ar148.pdf

Hellgren, J. 2007. Life cycle cost analysis of a car, a city bus and an intercity bus powertrain for year 2005 and 2020, Energy Policy 35(1): 39-49. https://doi.org/10.1016/j.enpol.2005.10.004

Horvath, A.; Matthews, H. S. 2005. Sustainability of transportation and other infrastructure systems, Journal of Infrastructure Systems 11(1): 1-1.

https://doi.org/10.1061/(ASCE)1076-0342(2005)11:1(1)

Jalonen, R.; Salmi, K. 2009. Safety Performance Indicators for Maritime Safety Management: Literature Review. Report No TKK-AM-9. Helsinki University of Technology, Finland. 63 p. Available from Internet: https://www.merikotka.fi/wp-content/uploads/2018/08/TKK-AM-9-1.pdf

Jun, H. K.; Kim, J. H. 2007. Life cycle cost modeling for railway vehicle, in 2007 International Conference on Electrical Machines and Systems (ICEMS), 8-11 October 2007, Seoul, South Korea, 1989-1994. 
Kinzhikeyev, S.; Wangai, A.W.; Kale, U. 2017. Influence of state management on environment sustainability, in Materials of International Practical Science Conference "Ualikhanov Readings - 21", 21 April 2017, Kokshetau, Kazakhstan, 6: 189-197.

Litman, T. A. 2009. Sustainable transportation indicators: a recommended research program for developing sustainable transportation indicators and data, in Transportation Research Board 88th Annual Meeting, 11-15 January 2009, Washington, DC, US, 1-14.

Maibach, M.; Schreyer, C.; Sutter, D.; Van Essen, H. P.; Boon, B. H.; Smokers, R.; Schroten, A.; Doll, C.; Pawlowska, B.; Bak, M. 2008. Handbook on Estimation of External Costs in the Transport Sector. Produced within the Study Internalisation Measures and Policies for All external Cost of Transport (IMPACT). Version 1.1. CE Delft, The Netherlands. 336 p. Available from Internet: https://ec.europa.eu/transport/sites/transport/files/themes/sustainable/doc/2008_costs_handbook.pdf

Messagie, M.; Lebeau, K.; Coosemans, T.; Macharis, C.; Van Mierlo, J. 2013. Environmental and financial evaluation of passenger vehicle technologies in Belgium, Sustainability 5(12): 5020-5033 https://doi.org/10.3390/su5125020

Michelberger, P.; Nádai, L. 2010. Development strategy for sustainable transportation: towards intelligent systems, Periodica Polytechnica Transportation Engineering 38(2): 99-104. https://doi.org/10.3311/pp.tr.2010-2.07

Norris, G. A. 2001. Integrating life cycle cost analysis and LCA, International Journal of Life Cycle Assessment 6(2): 118-120. https://doi.org/10.1007/BF02977849

Ntziachristos, L.; Gkatzoflias, D.; Kouridis, C.; Samaras, Z. 2009. COPERT: a European road transport emission inventory model, in I. N. Athanasiadis, A. E. Rizzoli, P. A. Mitkas, J. M. Gómez (Eds.). Information Technologies in Environmental Engineering. Environmental Science and Engineering, 491-504. https://doi.org/10.1007/978-3-540-88351-7_37

OECD. 2018. OECD Environmental Data and Indicators. Organisation for Economic Co-operation and Development (OECD). Available from Internet: http://www.oecd.org/env/ indicators-modelling-outlooks/data-and-indicators.htm

Profillidis, V. A.; Botzoris, G. N.; Galanis, A. T. 2014. Environmental effects and externalities from the transport sector and sustainable transportation planning - a review, International Journal of Energy Economics and Policy 4(4): 647-661.

Rigo, N.; Hekkenberg, R.; Ndiaye, A. B.; Hadhazi, D.; Simongati, G.; Hargitai, C. 2007. Performance assessment for intermodal chains, European Journal of Transport and Infrastructure Research 7(4): 283-300.

https://doi.org/10.18757/ejtir.2007.7.4.3400

Rohacs, D.; Rohacs, J. 2016. Magnetic levitation assisted aircraft take-off and landing (feasibility study - GABRIEL concept), Progress in Aerospace Sciences 85: 33-50.

https://doi.org/10.1016/j.paerosci.2016.06.001

Rohacs, D.; Voskuijl, M.; Rohacs, J.; Schoustra, R.-J. 2013. Preliminary evaluation of the environmental impact related to aircraft take-off and landings supported with ground based (MAGLEV) power, Journal of Aerospace Operations 2(3-4): 161-180. https://doi.org/10.3233/AOP-140040

Rohacs, J. 2010. Evaluation of the air transport efficiency definitions and their impact on the European personal air transportation system development, Transactions of the Institute of Aviation 205: 14-32.

Rohacs, J. 2005. Transportation - determining strategic element of the economy - characterization of recent and future, in Transport Means 2005: Proceedings of the 9th International Conference, 20-21 October 2005, Kaunas, Lithuania, 195-198.
Rohács, J.; Simongáti, G. 2007. The role of inland waterway navigation in a sustainable transport system, Transport 22(3): 148-153. https://doi.org/10.3846/16484142.2007.9638117

Samaras, C.; Meisterling, K. 2008. Life cycle assessment of greenhouse gas emissions from plug-in hybrid vehicles: implications for policy, Environmental Science \& Technology 42(9): 3170-3176. https://doi.org/10.1021/es702178s

Santero, N.; Masanet, E.; Horvath, A. 2010. Life Cycle Assessment of Pavements: a Critical Review of Existing Literature and Research. Prepared with the support of the Portland Cement Association through the Department of Energy under Contract No DE-AC02-05CH11231. University of California, US. 88 p. Available from Internet: https://escholarship.org/uc/item/8632v9cc

Santos, G.; Behrendt, H.; Maconi, L.; Shirvani, T.; Teytelboym, A. 2010. Part I: externalities and economic policies in road transport, Research in Transportation Economics 28(1): 2-45. https://doi.org/10.1016/j.retrec.2009.11.002

Simongáti, G. 2010. Multi-criteria decision making support tool for freight integrators: selecting the most sustainable alternative, Transport 25(1): 89-97. https://doi.org/10.3846/transport.2010.12

Smit, R.; Ntziachristos, L.; Boulter, P. 2010. Validation of road vehicle and traffic emission models - a review and metaanalysis, Atmospheric Environment 44(25): 2943-2953. https://doi.org/10.1016/j.atmosenv.2010.05.022

Tánczos, K.; Török, Á. 2006. Estimation method for emission of road transport, Periodica Polytechnica Transportation Engineering 34(1-2): 93-100.

Tanczos, K.; Torok, A. 2007. The linkage between climate change and energy consumption of Hungary in the road transportation sector, Transport 22(2): 134-138. https://doi.org/10.3846/16484142.2007.9638111

Upham, P.; Raper, D.; Thomas, C.; McLellan, M.; Lever, M.; Lieuwen, A. 2004. Environmental capacity and European air transport: stakeholder opinion and implications for modelling, Journal of Air Transport Management 10(3): 199-205. https://doi.org/10.1016/j.jairtraman.2003.10.016

Van Essen, H.; Scroten, A.; Otten, M.; Sutter, D.; Schreyer, C.; Zandonella, R.; Maibach, M.; Doll, C. 2008. External Costs of Transport in Europe: Update Study for 2008. CE Delft, The Netherlands. 163 p. Available from Internet: http://www.cer. be/sites/default/files/publication/2312_External_Costs_update_study_FINAL.pdf

Van Essen, H.; Van Wijngaarden, L.; Schroten, A.; Sutter, D.; Bieler, C.; Maffii, S.; Brambilla, M.; Fiorello, D.; Fermi, F.; Parolin, R.; El Beyrouty, K. 2019. Handbook on the External Costs of Transport. Version 2019. CE Delft, The Netherlands. 351 p. https://doi.org/10.2832/27212

WCED. 1987. Our Common Future. World Commission on Environment and Development (WCED). Oxford University Press. 383 p.

WRI. 2018. CAIT Climate Data Explorer. World Resources Institute (WRI), Washington, DC, US. Available from Internet: http://cait.wri.org 